\title{
Carcinoma de los conductos colectores de Bellini: una alteración poco frecuente y de mal pronóstico
}

\section{Carcinoma of the collecting ducts of Bellini: a rare entity with a poor prognosis}

Gutiérrez-Domingo A, ${ }^{1}$ Gutiérrez-Domingo I, ${ }^{2}$ Gallardo-Rodríguez KM, ${ }^{3}$ Rodríguez-Caulo $\mathrm{AP}^{4}$

\section{Sr. Editor:}

El carcinoma de los conductos colectores de Bellini es un tumor renal poco frecuente, pues representa menos de $1 \%$ del total de las neoplasias renales, ${ }^{1}$ también llamado carcinoma del conducto colector o carcinoma del conducto de Bellini. Tiene su origen en las células principales de los conductos de Bellini. Según la OMS, aparece entre los 13 y 83 años de edad, principalmente en el sexo masculino (relación varón-mujer de 2:1). ${ }^{1}$ Clínicamente, los pacientes manifiestan dolor abdominal y hematuria. Cerca de un tercio expresan metástasis al diagnóstico y el pronóstico es malo. Desde el punto de vista macroscópico, se localizan en la porción central del riñón, miden de 2.5 a $12 \mathrm{~cm}$, con bordes irregulares y superficie de corte blanco-grisácea. Pueden observarse focos de necrosis y nódulos satélites. Frecuentemente invaden el tejido adiposo del seno renal y perirrenal.

Presentamos el caso de un varón de 64 años de edad, con antecedentes personales de hipercolesterolemia, hipertensión arterial, diabetes mellitus tipo 2 y esteatosis hepática, que consultó en el servicio de Urgencias por dolor en la fosa renal izquierda de varios días de evolución y fiebre. A la exploración general se apreció puño-percusión positiva en la fosa renal izquierda y

\footnotetext{
${ }^{1}$ Residente de Anatomía Patológica, Hospital Universitario Virgen Macarena, Sevilla, España.

${ }^{2}$ Adjunto del servicio de Medicina Interna, Hospital San Juan de Dios, Bormujos (Sevilla), España.

${ }^{3}$ Adjunto del servicio de Anatomía Patológica, Hospital Nuestra Señora de Candelaria, Santa Cruz de Tenerife, España.

${ }^{4}$ Adjunto del servicio de Anatomía Patológica, Complejo Hospitalario Llerena-Zafra, Badajoz, España.
}

Recibido: marzo 2017

Aceptado: mayo 2017

Correspondencia

Dr. Álvaro Gutiérrez Domingo

agutierrezdomingo@gmail.com

Este artículo debe citarse como Gutiérrez-Domingo A, Gutiérrez-Domingo I, Gallardo-Rodríguez KM, Rodríguez-Caulo AP. Carcinoma de los conductos colectores de Bellini: una alteración poco frecuente y de mal pronóstico. Rev Mex Urol. 2017 mayo;77(3):244-246. 
fiebre de $38^{\circ} \mathrm{C}$. Los estudios de laboratorio reportaron leucocitosis con desviación a la izquierda y elevada concentración de proteína $\mathrm{C}$ reactiva. El tratamiento prescrito para el dolor fue poco efectivo, por lo que se decidió ingresarlo para observación. Posteriormente se le realizó tomografía abdominal, que reveló una masa renal izquierda, de $5 \mathrm{~cm}$ de dimensión máxima, de aspecto necrótico, que infiltraba el músculo psoas, con adenopatías en el hilio renal, marcados cambios inflamatorios y discreto derrame pleural izquierdo. Además, al paciente se le practicó una gammagrafia ósea que detectó hipercaptación en los arcos costales. Estos hallazgos coincidieron con una tumoración sobreinfectada, con marcada afectación perirrenal y lesiones sugerentes de metástasis en las bases pulmonares y óseas. Se decidió efectuar nefrectomía izquierda y administración de quimioterapia. El paciente falleció a los 8 meses del posoperatorio.

La pieza de la nefrectomía pesaba 855 g y medía $14 \times 8 \times 7 \mathrm{~cm}$. En el análisis macroscópico, en el polo inferior, se identificó un área mal definida, blanco-pardusca, de $4.5 \times 3 \mathrm{~cm}$ de dimensión máxima, de aspecto tumoral, que parecía extenderse a la pelvis renal y a la primera porción del uréter. La neoplasia infiltraba el tejido adiposo del seno renal y perirrenal. La tumoración no afectaba al borde de resección ureteral.

En el estudio microscópico se observó un patrón de crecimiento túbulo-papilar, con glándulas irregulares que infiltraban el parénquima renal y un estroma desmoplásico. Las células mostraban alto grado nuclear (grado 4 de Führman), con patrón en tachuela y citoplasma eosinófilo. El tumor tuvo inmunorreacción positiva para citoqueratina de alto peso molecular (CK34ßE12). De acuerdo con los hallazgos histológicos e inmunohistoquímicos se estableció el diagnóstico de carcinoma de los conductos colectores G4 de Führman (Figura 1).
Desde el punto de vista histológico, existen criterios diagnósticos mayores y menores que caracterizan a esta neoplasia. Entre los criterios mayores destaca una arquitectura típica de túbulos irregulares, con alto grado nuclear, inmunorreación para citoqueratinas de alto peso molecular, estroma desmoplásico y ausencia de neoplasia urotelial. Como criterios menores: se observa un patrón papilar, afectación extrarrenal, invasión linfovascular y atipia intratubular adyacente a la neoplasia. Inmunohistoquímicamente expresa positividad intensa para citoqueratinas de alto peso molecular (CK34ßE12 y CK19). ${ }^{2}$

El diagnóstico diferencial se establece con: carcinoma papilar de células renales, adenocarcinoma o carcinoma urotelial con diferenciación glandular y adenocarcinoma metastático.

Respecto de la histogénesis, el tumor se origina en las células principales de los conductos de Bellini. De acuerdo con la bibliografía, se han detectado alteraciones en el cromosoma 1 y deleciones en $6 p, 8 p, 13 q$ y $21 q$. $^{2}$ También se han descrito amplificaciones del gen Her2/neu, en contraposición con lo que ocurre en el carcinoma de células claras. ${ }^{3}$

El pronóstico es desfavorable. Un tercio de los pacientes expresa metástasis al diagnóstico y dos tercios fallece en los 2 primeros años del mismo. ${ }^{4}$ Debido a su malignidad, el protocolo de tratamiento actual consiste en nefrectomía y quimioterapia siilar al que se indica en pacientes con carcinomas transicionales infiltrantes. ${ }^{5}$

Expusimos un nuevo caso de carcinoma de los conductos colectores de Bellini, excepcional, con características clínicas, radiológicas, histológicas e inmunofenotípicas que coinciden con lo reportado en la bibliografía. 


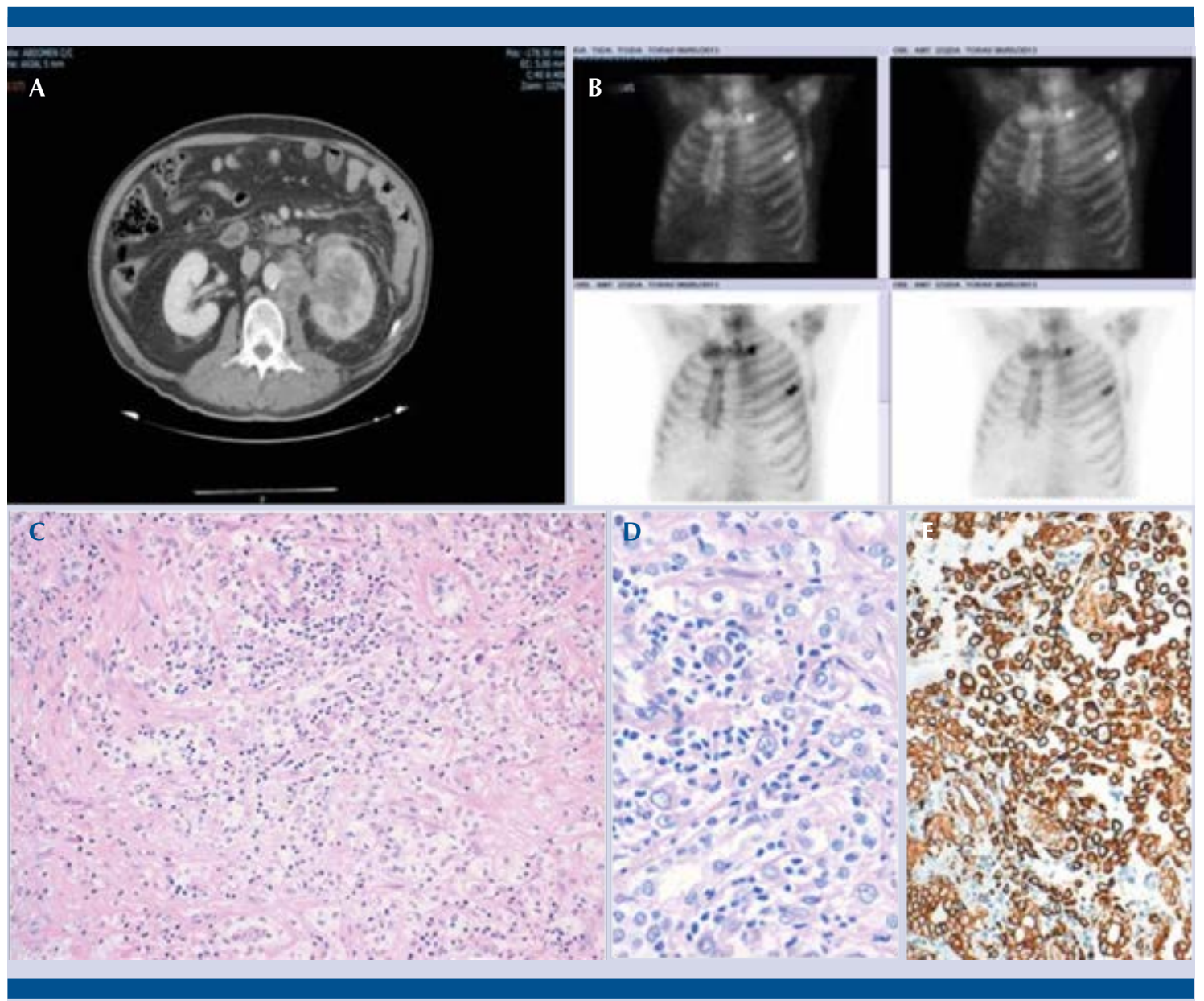

Figura 1. Carcinoma de los conductos colectores de Bellini. A) Tomografía abdominal: masa renal izquierda, de $5 \mathrm{~cm}$ de dimensión máxima, aspecto necrótico y marcados cambios inflamatorios. B) Gammagrafía ósea: captación metabólica en arco costal, sugerente de metástasis. C) Neoplasia con patrón de crecimiento túbulopapilar, glándulas irregulares que infiltran el parénquima renal y estroma desmoplásico (H-E,10x). D) A mayor aumento se aprecian las células tumorales en tachuela, con alto grado nuclear (grado 4 de Führman) y citoplasma eosinófilo (H-E, 40x). E) Intensa inmunotinción para citoqueratina de alto peso molecular (CK34ßE12, 20x).

\section{REFERENCIAS}

1. Eble JN, Sauter G, Epstein JI, Sesterhenn IA (Eds). World Health Organization Classification of Tumours. Pathology and Genetics of Tumours of the Urinary System and Male Genital Organs. Lyon: IARC Press, 2004;10.

2. Polascik TJ, Cairns P, Epstein JI, Fuzesi L, Ro JY, Marshall FF, Sidransky D, Schoenberg M (1996). Distal nephron renal tumors: microsatellite allelotype. Cancer Res 56: 1892-1895.
3. Selli C, Amorosi A, Vona G, Sestini R, Travaglini F, Bartoletti $R$, Orlando C (1997). Retrospective evaluation of c-erbB-2 oncogene amplification using competitive PCR in collecting duct carcinoma of the kidney. J Urol 158: 245-247.

4. Srigley JR, Eble JN (1998). Collecting duct carcinoma of kidney. Semin Diagn Pathol 15: 54-67.

5. Peyromaure $M$, Thiounn N, Scotte F, Vieillefond A, Debre B, Oudard S. Collecting duct carcinoma of the kidney: a clinicopathological study of 9 cases.

6. J Urol. 2003;170(4 Pt 1):1138-40. 